\title{
Group Performance Variables of the Self-Help Groups (SHGs) under Deendayal Antyodaya Yojana - National Rural Livelihood Mission (DAY-NRLM)
}

\author{
Pratima Rana* and Neelam Bhardwaj
}

Department of Agricultural Communication, GBPUAT, Pantnagar,
U.S. Nagar, Uttarakhand, India

*Corresponding author

\begin{tabular}{|l|}
\hline Ke y w o r d s \\
Live lihood \\
enhancement, \\
$\begin{array}{l}\text { Universal social } \\
\text { mobilization, } \\
\text { Financial inclusion }\end{array}$ \\
\hline Article Info \\
\hline $\begin{array}{l}\text { Accepted: } \\
12 \text { November } 2020 \\
\text { Available Online: } \\
\text { 10 December } 2020\end{array}$ \\
\hline
\end{tabular}

\section{Introduction}

The success of achieving the goal of sustainable development of our country lies in

empowering rural India where 69 per cent of

\section{A B S T R A C T}

The government of India since independence has implemented various programmes to alleviate poverty. The poverty alleviation programmes were classified into selfemployment, wage employment, food security and social security programmes and their main focus is on self-employment programmes (Yesudian, 2011). Schemes like Development of Women and Children in Rural Areas (DWACRA), Integrated Rural Development Programme (IRDP), Supply of Improved Toolkits for Rural Artisans (SITRA) and Training of Rural Youth for Self employment (TRYSEM) were implemented in a row after Community Development Programme (CDP) in 1952. After lots of thinking and introspection of previous schemes, a new philosophy and approach saw the light of the day and Swarn Jayanati Grameen Swarojgar Yojna (SGSY) was restructured as National Rural Livelihood Mission (NRLM), the strategy is to encourage women in rural households to be part of a self-help group. The world's largest poverty alleviation programme evolved as a national movement in 2011 and became National Rural Livelihoods Mission (NRLM). The three pillar of NRLM includes universal social mobilization, financial inclusion and livelihood enhancement. A study has been undertaken to access the various group analysis variables of the Self-Help Groups (SHGs) in the light of NRLM-Aajeevika in the Uttarakhand state. The data was collected by using appropriate interview schedule in the two districts i.e. Dehradun and Udham Singh Nagar of Uttarakhand state. The group variables under study include group process, participation, task function, maintenance function, group atmosphere and interpersonal trust. The results showed that majority of the women members had medium level of overall group performance followed by 21.07 per cent and 12.17 percent with high and low level of overall group performance respectively. its population resides. Realizing the significance of rural development, India has adopted various innovative strategies and approaches for ensuring the basic rights of the rural population. In spite of rapid growth of 
Gross Domestic Product (GDP) in India, a large rural population of the country still lives below poverty line (BPL). Different studies estimated the rate of rural poverty at different levels. In spite of the numerous efforts, the rural poverty continues to be a major challenge to the Government at all levels. To address the challenge of rural poverty, the Ministry of Rural Development conceived a mission mode scheme titled as National Rural Livelihood Mission (NRLM) in the year 2011. NRLM was renamed as DAY-NRLM (Deendayal Antyodaya Yojana - National Rural Livelihood Mission) with effect from March 29, 2016. It is a centrally sponsored scheme and the Central and State Governments jointly fund the projects. It is also known as National Rural Livelihood Mission-Aajeevika.

The core belief of National Rural Livelihoods Mission is that the poor have innate capabilities and a strong desire to come out of poverty and poor were willing to be organized. The challenge is to unleash their capabilities to generate meaningful livelihoods and enable them to come out of poverty. NRLM works on three pillars universal social mobilization, financial inclusion and livelihood enhancement.

As the Institutions of Poor (IoP) mature (SHGs, federation, cluster level and other collectives of poor), they were facilitated to take up livelihood or income generating activities. The poorest, most vulnerable and the marginalized people were identified by the Participatory Identification of Poor (PIP) to form SHGs, village federations, cluster and beyond. NRLM provides universal access to the affordable cost-effective reliable financial services to the poor like financial literacy, bank account, savings, credit, insurance, remittance, pension and counselling on financial services. This study was inspired by the fact that, despite considerable interest in
SHG-based approaches to micro-finance, rigorous evaluations of the impact of such intervention were still scant and that even studies pointing to clear social, empowerment and nutritional impacts were unable to ascertain economic effects. The fact that SHGs has great potential in accelerating the pace of rural development, it is high time that we analyse the group development from the close corner. This will provide the insight over the loophole in existing system and the hidden potentials, which were yet to be explored. Therefore, to assess the outcomes and provide empirical feedback based on systematic evaluation research methods, an investigation was proposed. Also to understand the various group variables which were necessary for the overall group performance of SHGs the study was undertaken.

The main objectives of this study include to study the various group performance variables of SHGs formed under DAY-NRLM. And also to measure the overall group performance of the SHGs under DAYNRLM.

\section{Materials and Methods}

Uttarakhand (known as "Devbhoomi") constitutes the universe for the present study and it is the $27^{\text {th }}$ state of Republic of India. The scenic, religious and beautiful state of Uttarakhand formerly known as Uttaranchal was carved out of the state of Uttar Pradesh in 2000. Out of the 13 districts in the Uttarakhand state, only two districts Udham Singh Nagar and Dehradun were selected for having sufficient number of SHGs under USRLM. For the study purpose, out of the six development block of Dehradun district, namely Doiwala, Chakrata, Raipur, Sahaspur and Vikasnagar. Two blocks Doilwala and Sahaspur were selected purposively having the maximum number of SHGs present in the 
study areas. Further for the study in the Udham Singh Nagar District, there were seven development block viz. Bajpur, Gadarpur, Jaspur, Kashipur, Rudrapur, Sitarganj and Khatima. For the present investigation two blocks Sitarganj and Khatima were selected purposively based on maximum number of SHGs present in the study area. The lists of SHGs were obtained from the State Rural Livelihood Mission office located at different development blocks selected for the study. Out of which, total twenty eight SHGs were selected randomly for the study purpose i.e. Seven Self-Help Groups from each block. The criterion for the selection of Self-Help Groups is as follows:

The selected Self-Help Groups should have existed for minimum period of three years.

Each selected Self-Help Groups should not have less than ten members.

The selected SHGs women members i.e. 280 were interviewed and the various group variables like group process, participation, task function, maintenance function, interpersonal trust and group atmosphere were measured by asking responses for the various statements about each variable under study.

\section{Results and Discussion}

\section{Group variables}

Group variables were the backbone of the SHGs and their effective working. The group performance variables under study were group process, participation, task function, maintenance function, interpersonal trust, group atmosphere. The six group variables were described below:

\section{Group process}

It refers to the general process that occurs during interactions within the group members particularly processes of social influence. It basically describes about the regularities in behavior shown by group members which included group norms and shared expectations between them. The data in Table 1 revealed that majority of the women members were showing high performance (95\%) in the group process. The women in the SHGs were vocal about their opinion also they shared a common goal and work jointly towards the achievement of that particular goal. Majority i.e. 44.30 per cent of the respondents fall under high level of group process in the study of Vaish (2004). Other studies were Sharma and Sohal (1977), Kumar et al., (2018) who also reported the same. The findings were in line with the study of Setia and Tandon (2017).

\section{Participation}

It indicated the extent of involvement shown by the women members in each and every aspect of the group functioning. It was defined as the degree to which the women members were involved in group meeting, discussion and group activities of Self-Help Groups. Data presented in Table 2 revealed that majority $(55 \%)$ of the respondents had medium level of participation in the SHGs followed by 41.43 per cent with high level of participation and 3.57 per cent with low level of participation in the group functioning, working, decision making. The reason for medium level of participation might be as most of the members were agricultural labourers, so they were unable to participate actively in SHGs also lack of time was a constraint. The leaders' position taken up by the group members' was done on consensus basis and they all participate in all the group activities as and when they get a chance to be the part of the group activity. The results were in line with the study of Singh and Jain (1995) and Vaish (2004) who also reported that 58.23 per cent of the respondents had medium level of participation in group activities. 


\section{Task function}

It refers to the degree to which respondents makes suggestions to tackle a problem in SHG, summarizes what has been covered in the group, tries to give or ask for facts, ideas, opinion feelings, feedback etc. and keep the group on target. Task function includes initiating, information seeking, information giving, opinion seeking, clarifying, elaborating, coordinating, developing procedure and summarizing. The finding of the study as shown in Table 3 revealed that majority $(52.14 \%)$ of the women members were motivated towards the high level of task function followed by 40.71 per cent with medium level of task function and only 7.14 per cent with low level of task function. The findings were in correspondence with the study of Vaish (2004) who also found that 51.89 percent of the respondents were high in task functions. Also the study was in line with Cole (1987) and Singh et al., (2007).

Table.1 Distribution of women members on the basis of group process of SHGs ( $\mathrm{n}=280$ )

\begin{tabular}{|c|c|c|c|}
\hline S.No. & Category & Frequency & Percentage \\
\hline $\mathbf{1}$ & Low & 00 & 0.00 \\
\hline $\mathbf{2}$ & Medium & 14 & 5.00 \\
\hline $\mathbf{3}$ & High & 266 & 95.00 \\
\hline
\end{tabular}

Table.2 Distribution of women members on the basis of participation of group members in SHGs $(\mathrm{n}=280)$

\begin{tabular}{|c|c|c|c|}
\hline S.No. & Category & Frequency & Percentage \\
\hline $\mathbf{1}$ & Low & 10 & 3.57 \\
\hline $\mathbf{2}$ & Medium & 154 & 55.00 \\
\hline $\mathbf{3}$ & High & 116 & 41.43 \\
\hline
\end{tabular}

Table.3 Distribution of women members on the basis of task function of SHGs ( $\mathrm{n}=280$ )

\begin{tabular}{|c|c|c|c|}
\hline S.No. & Category & Frequency & Percentage \\
\hline $\mathbf{1}$ & Low & 20 & 7.14 \\
\hline $\mathbf{2}$ & Medium & 114 & 40.71 \\
\hline $\mathbf{3}$ & High & 146 & 52.14 \\
\hline
\end{tabular}

Table.4 Distribution of women members on the basis of maintenance function of SHGs $(n=280)$

\begin{tabular}{|c|c|c|c|}
\hline S.No. & Category & Frequency & Percentage \\
\hline $\mathbf{1}$ & Low & 12 & 4.29 \\
\hline $\mathbf{2}$ & Medium & 159 & 56.79 \\
\hline $\mathbf{3}$ & High & 109 & 38.93 \\
\hline
\end{tabular}


Table.5 Distribution of women members on the basis of interpersonal trust of SHGs $(n=280)$

\begin{tabular}{|c|c|c|c|}
\hline S.No. & Category & Frequency & Percentage \\
\hline $\mathbf{1}$ & Low & 07 & 2.5 \\
\hline $\mathbf{2}$ & Medium & 164 & 58.57 \\
\hline $\mathbf{3}$ & High & 109 & 38.93 \\
\hline
\end{tabular}

Table.6 Distribution of women members on the basis of group process of SHGs $(n=280)$

\begin{tabular}{|c|c|c|c|}
\hline S.No. & Category & Frequency & Percentage \\
\hline $\mathbf{1}$ & Low & 00 & 0.00 \\
\hline $\mathbf{2}$ & Medium & 50 & 17.86 \\
\hline $\mathbf{3}$ & High & 230 & 82.14 \\
\hline
\end{tabular}

Table.7 Distribution of women members on the basis of group variables $(n=280)$

\begin{tabular}{|c|c|c|c|c|}
\hline S.No. & Category & Range/Score & Frequency & Percentage \\
\hline $\mathbf{1}$ & Low & Less than 49 & 34 & 12.17 \\
\hline $\mathbf{2}$ & Medium & $49-67$ & 187 & 66.79 \\
\hline $\mathbf{3}$ & High & More than 67 & 59 & 21.07 \\
\hline
\end{tabular}

\section{Maintenance function}

It refers to the extent to which women members helps others in group activities of SHG, helping them or interrupting them in group discussion, feels the other members were cooperative and listening, perceives other members feel good/bad when ideas were accepted/rejected in the group and the extent to which others members attempts to maintain task functions of SHG. Maintenance function comprised of encouraging, expressing feelings, having fun, compromising, facilitating communication, setting standards and goals, interpreting, listening, following and declaring success to the group members. Table 4 suggested that 56.79 per cent of the women members were on the medium level of maintenance function while 38.93 per cent had high level of maintenance function followed by 4.29 per cent with low level. The study was in line with the Vaish (2004) and Singh et al., (2007) who reported 25.95 per cent of respondent had medium level of maintenance function.

\section{Interpersonal trust}

It is the degree to which the members of the group trust each other. The finding in Table 5 revealed that majority i.e. 58.57 per cent of the women had medium level of interpersonal trust within the group followed by 38.93 per cent had high level of interpersonal trust. Only 2.5 per cent had low level of interpersonal trust between the SHGs formed by NRLM. Vaish (2004) found that around 40.50 per cent of the members had medium level of interpersonal trust. Similar results were found by Singh et al., (2007), Bharamappanavara and Jose (2015) and Nayak (2015).

\section{Group atmosphere}

The group atmosphere is determined by the speed of conflict resolution, great work climate and friendly congenial atmosphere in 
the SHGs. Data in the Table 6 revealed that a high level $(82.14 \%)$ of satisfaction was there in the SHG groups as the atmosphere in the group was friendly followed by medium level i.e. only 17.86 per cent. The findings were in line with Singh and Singh (2001) and Kumar and Singh (2002).

\section{Overall group performance}

The group performance was measured by adding the total score obtained from the group members and then categorizing them into three categories i.e. 'low', 'medium' and 'high'. The overall performance of the group was measured by combining all the variables score. The results were depicted in table 7 , it was found that the majority of the women members of the SHGs under DAY-NRLM had medium level $(66.79 \%)$ of overall group performance followed by 21.07 per cent and 12.17 percent with high and low level of overall group performance respectively.

In conclusion the overall group performance of the SHGs was measured by using group process, participation, task function, maintenance function, interpersonal trust and group atmosphere variables. It was found that majority of the groups had medium level of group performance which is due to the reason that women members were still hesitant to take up the leadership roles and also to take initiative for every group activity. The group member participation was also medium which lead to the average group performance. Only some of the groups i.e. $21.07 \%$ had high level of group performance and working very effectively in the respective areas under NRLM.

\section{Acknowledgement}

The information, time and help provide by the SHGs were gratefully acknowledged. Also the help and support provided by Block
Mission Management Units (BMMUs) of all the four blocks, namely Sitarganj, Khatima, Sahaspur and Doiwala were gratefully acknowledged.

\section{References}

Bharamappanavara, S. C. and Jose, M. 2015. Group Dynamics and Collective Performance of Self-Help Groups under Different Microcredit Delivery Models in Karnataka. Agriculture Economics Research Review, 28(1): 127-138.

Cole, N. S. 1987. Task Role Communication and Ecology of Mind. San Francisco. Chandler Pub. Co.

Kumar, R., Suar, D., and Mishra, P. 2018. Characteristics for the Effectiveness of Women's Self-Help Groups in Bihar. VOLUNTAS: International Journal of Voluntary and Nonprofit Organizations, 29(6): 1283-1299.

Kumar, V. P. and Singh, B. 2002. Dimensions of Self Help Group Dynamics of Horticulture Farmers. Indian Research Journal of Extension Education, 2(1): 612.

Nayak, A. K. 2015. Developing Social Capital through Self-Help Groups. Indore Management Journal, 7(1): 18-24.

Setia, M. and Tandon, M. S. 2017. Impact Study of Women Empowerment through Self-Help Groups-A Study of Haryana. Global Journal of Enterprise Information System, 9(2): 50-53.

Sharma, O. P. and Sohal, T. S. 1977. Study of Factors Contributing to Effective Coordination under Indo German Agricultural Package Project, Mandi, Himachal Pradesh. Indian journal of extension education.

Singh, K. and Jain, T. S. R. 1995. Evolution and Survival of SHGs: Some Theoretical Proposition and Empirical Evidences. Working Paper 4, Bankers Institute of 
Development.

Singh, R.P. and Singh, B.B. 2001. Cohesiveness makes a Group Dynamic: An Overview. Indian Journal of Extension Education, 1(2): 8-14.

Singh, Y. K., Kaushal, S. K., and Gautam, S. S. 2007. Performance of Women's Self Help Groups (SHGs) in District Moradabad, UP. International Journal of Rural Studies, 14(2).
Vaish, S. 2004. Performance Assessment of Women Self-Help Groups (SHGS)-A Study in Udham Singh Nagar Uttaranchal (Doctoral dissertation, GB Pant University of Agriculture and Technology Pantnagar, Uttarakhand).

Yesudian, C. A. 2011. Poverty alleviation programmes in India: A social audit.

\section{How to cite this article:}

Pratima Rana and Neelam Bhardwaj. 2020. Group Performance Variables of the Self-Help Groups (SHGs) under Deendayal Antyodaya Yojana - National Rural Livelihood Mission (DAY-NRLM). Int.J.Curr.Microbiol.App.Sci. 9(12): 1640-1646.

doi: https://doi.org/10.20546/ijcmas.2020.912.195 